\title{
Physical activity advocacy and promotion: The South African experience
}

\author{
T L Kolbe-Alexander, F Bull, E V Lambert \\ UCT/MRC Research Unit for Exercise Science and Sports Medicine, Faculty of Health Sciences, University of Cape Town \\ T L Kolbe-Alexander, PhD \\ E V Lambert, PhD
}

British Heart Foundation National Centre for Physical Activity and Health, Loughborough University, United Kingdom and School of Population Health, University Western Australia

F Bull, PhD

Corresponding author: T Kolbe-Alexander(tracy.kolbe-alexander@uct.ac.za)

\begin{abstract}
Background. The global mandate by the WHO World Health Report of 2002, Global Strategy for Diet, Physical Activity and Health, were mirrored by the policy environment in South Africa. The 'Vuka South Africa - Move for your Health' campaign was an example of an initiative adopted by national government, promoting physical activity (PA) for health.

Methods. This manuscript describes the process, events and lessons learned during the initial phase of Vuka SA from 2004 to 2010 . Data were obtained from the grey literature, minutes and reports of meetings and from stakeholders.

Results. Utilising a multi-sectoral approach, this initiative was partnered by governmental and non-governmental organisations, the private sector and tertiary institutions. The main anticipated short-term outcome was an increased awareness of the message ('move for your health'), with a view to achieving increased population levels of participation in health-enhancing physical activity over the long term. Vuka SA was initiated by the National Department of Health and launched in 2005. Subsequently, 36 partner organisations participated in two national workshops, who together with provincial health promoters undertook to promote the campaign. This was followed by an international training course on PA and public health for policy makers and programme implementers, and the subsequent call for the development of an African Physical Activity Network.

Discussion. Although the campaign has not yet undergone rigorous evaluation and participation at present appears to be modest, there are promising examples of multi-sectoral awareness and advocacy activities resulting in some national dissemination of the role of PA in health promotion.
\end{abstract}

S Afr J SM 2012;24(4):112-116. DOI:10.7196/SAJSM.349

In 2002, the World Health Organization's (WHO) report on reducing risks and promoting healthy living recognised physical inactivity as one of the major modifiable risk factors for developing non-communicable diseases (NCDs) and global mortality and morbidity, along with tobacco use, unhealthy eating and obesity, and excessive alcohol intake. ${ }^{1}$ Consequently, creating a public health message emphasising the benefits of regular physical activity which aimed to promote positive lifestyle and behaviour change became increasingly important.

Placing this in a South African (SA) context, where there is a quadruple burden of disease, NCDs account for more than onethird (37\%) of all deaths. ${ }^{2}$ This is juxtaposed with $57 \%$ of SA women and nearly $30 \%$ of men who are overweight or obese. ${ }^{2}$ Furthermore, only $36 \%$ of SA men and $24 \%$ of women report sufficient levels of daily health-enhancing physical activity. ${ }^{3}$ Similarly, the SA Youth Risk Behaviour Survey has found that more than one-third of all adolescents report insufficient levels of physical activity. ${ }^{4}$ Moreover, $30 \%$ of ischaemic heart disease, $27 \%$ of colon cancer, and $20 \%$ of diabetes in SA have been attributed to physical inactivity. Thus, there is a major health imperative to promote physical activity (PA) and reduce levels of inactivity in the general South African population.

In the context of global and national trends for rising prevalence of obesity, inactivity and NCD, and in part, in response to the WHO's mandate to promote PA and health, the 'Vuka South Africa - Move for your Health' (Vuka SA) campaign was initiated in 2004/2005. The aim of this report is to document the process of developing the Vuka SA campaign and to identify factors, including the policy environment, that may have influenced the development and progress of such a campaign in countries like SA, which have important competing health agendas such as HIV/AIDS, and wide demographic and socioeconomic disparities. We describe the factors influencing the initiation of the Vuka SA campaign, to the launch in 2006, and subsequent activities until 2010.

\section{Methods}

Sources of information

Data in the form of reports and notes from meetings were obtained from the NDOH's Health Promotion Unit, Provincial Department of Health's Health Promotion Officers, grey literature and members of the inter-sectoral Vuka SA task team.

\section{Expected outcomes}

The Vuka SA campaign logic model is presented in Fig. 1. The primary expected outcome of the Move for Health campaign was a greater awareness of the role of PA for promoting health. Intermediate 


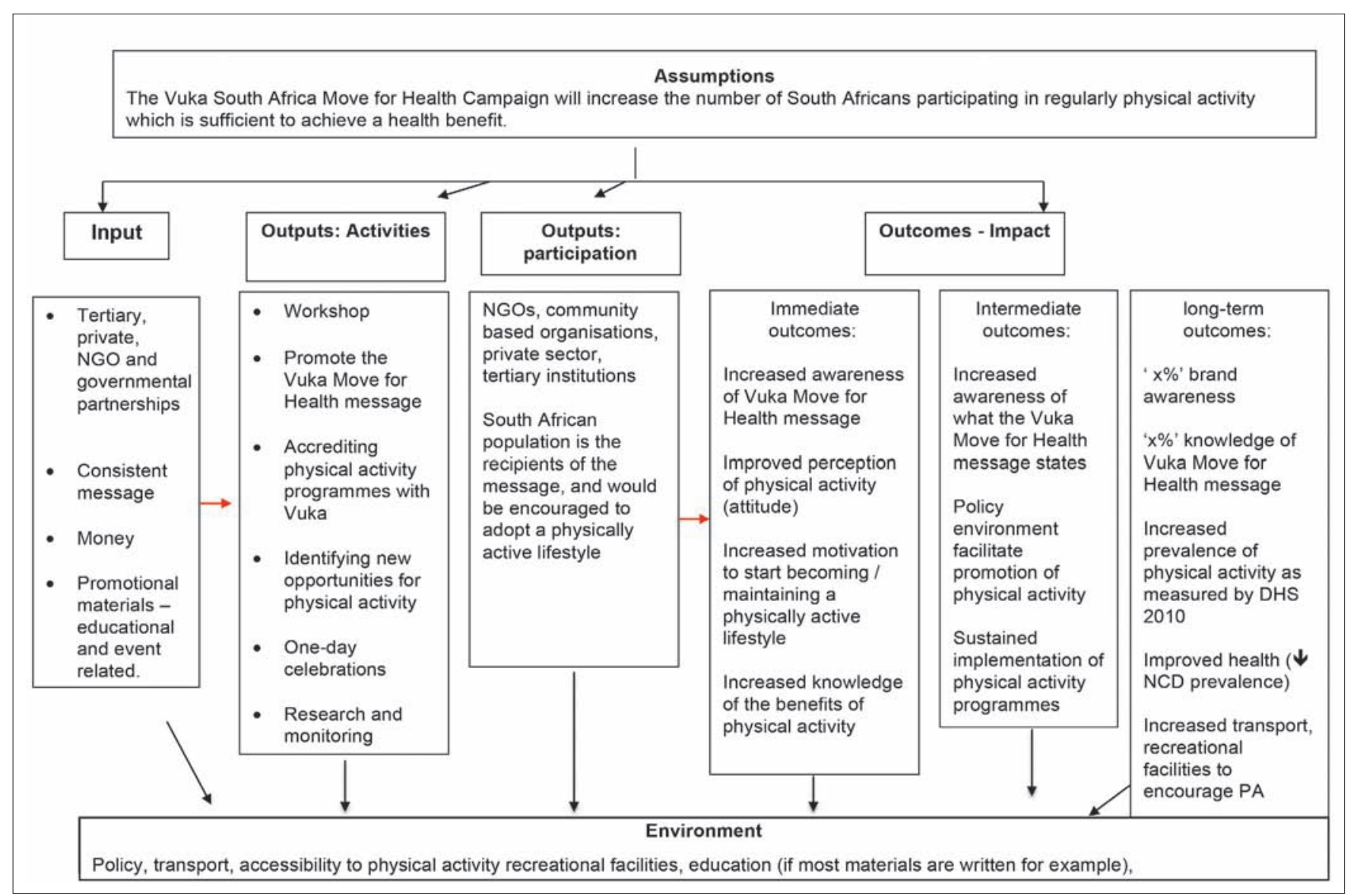

Fig. 1. Logic model of Vuka South Africa - Move for your Health.

outcomes included an expanded reach of the message, implementation of supportive policy, changing social norms towards PA, leading to increased participation.

\section{Description and interpretation of results}

The formative events and the process of implementation of Vuka are reported on, according to the information sources, and have been arranged chronologically. Where data on reach and implementation are available, these have been presented. There are no available data on secular trends in population-based PA prevalence. The first time PA was included in a national health survey was in 2004; this is planned to be repeated in 2012, therefore describing the trends in PA for SA is beyond the scope of this paper.

\section{Results}

Formative global and national policy environment and initiatives (1990s)

Fig. 2 provides a schematic of the national and global events and chronology leading to the development and launch of the Vuka SA campaign.

The early-to-mid 1990s in SA were characterised by seminal events, including the abolition of Apartheid and the first free national government elections. The eradication of Apartheid resulted in the increased equal access to health care, sporting and recreational facilities and education. ${ }^{6}$ During the same period, public and private sector partnerships governmental and non-governmental organisations (NGOs) and tertiary institutions developed and implemented various community-based intervention programmes focusing on the promotion of PA. ${ }^{6,7}$ There was limited evaluation, programmes often occurred in 'silos', and there was an absence of a national, multi-sectoral written plan aimed at improving health status through increased PA among SA.

Concurrently, PA was receiving increasing global attention and recognition as a modifiable risk factor for NCDs in both developed and developing countries. The US Surgeon General's Report on Physical Activity, first published in 1995, advocated the accumulation of 30 minutes of moderate intensity on at least 5 days of the week. ${ }^{8}$ This recommendation facilitated the development of a unified message for the prescription of PA for health. In response to this global trend, and due to the high prevalence of inactivity and NCDs, Agita Sao Paulo was launched in 1996 in the state of Sao Paulo, Brazil.9 This programme was initiated by a non-governmental research and teaching institute based in Sao Paulo (CELAFISCS), and was an example of a mass participation campaign advocating 30 minutes of PA at least 5 days per week among Brazilians.'

Further to the success of Agita on a national and regional platform, the WHO adopted this focus for World Health Day in 2002, which resulted in the establishment of the Agita Mundo/Move for Health, global campaign. The Move for Health slogan was translated into 63 languages, enabling 148 countries to organise 1987 events around the world in $2002 .^{10}$

\section{Move for Health Day (2002)}

The National Department of Health (NDOH), together with the local WHO office, were the driving forces behind the 2002 Move for Health campaign. The main national event in 2002 took place in the 


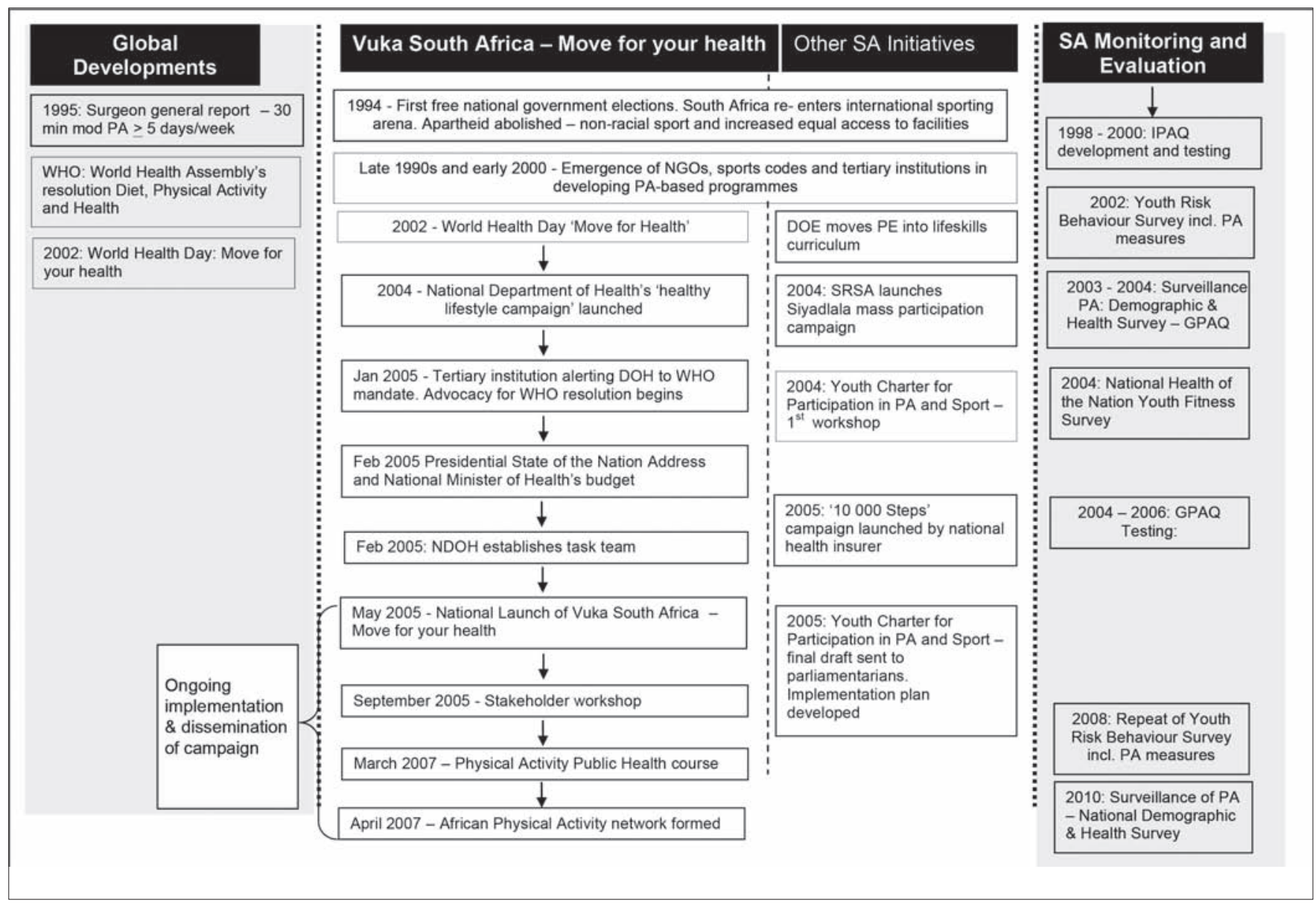

Fig. 2. Schematic of the development of the Vuka South Africa - Move for your Health campaign: 1994 - 2008.

Gauteng Province and was comprised of a street parade, followed by formal speeches by government officials. This event also focused on community participation in recreational activities including indigenous games and dancing, which were organised by the National Department of Sports and Recreation. ${ }^{11}$

In other provinces, local Departments of Health hosted free health screening and PA promotions for their employees, and communities were encouraged to support and stage local events. The main focus of these events was to celebrate and encourage participation in PA. Unfortunately, at the time of implementation, monitoring and evaluation received little attention, and the exact number of events and participants are unknown.

\section{Healthy Lifestyles campaign (2004 - 2007)}

Subsequent to Move for Health Day (2002), the NDOH's Healthy Lifestyles campaign was launched. This campaign formed part of the national plan for comprehensive health care in SA, and was one of the strategic priorities for the period $2004-2009 .{ }^{12}$ The campaign had five main pillars, which included promotion of PA, healthy nutrition, tobacco control, responsible sexual behaviour and combatting the abuse of alcohol. Programmes and activities included routine $2-5-\mathrm{km}$ walks within strategically selected communities. This was followed by mass public preventive health-risk screening. The context of the 'Healthy Lifestyles' days provided opportunities to promote regular PA and ongoing dissemination of the important message 'Move for your Health'. Approximately 2400 adults were screened and participated in these events annually (2004 - 2007).

\section{Operationalising Vuka SA}

In response to the WHO Global Strategy for Diet and Physical Activity for Health, academics approached the NDOH's Health Promotions Unit in February 2005, highlighting the importance of implementing a 'Move for Health Day' campaign in SA. Government officials were receptive to the message, which was compatible with the 'Healthy Lifestyles' campaign. Two meetings followed to discuss potential strategies to promote this campaign to other stakeholders and service providers in SA. Following these meetings, the NDOH invited other governmental departments, NGOs, tertiary institutions and representatives from the private sector to be part of a task team.

The initial team was comprised of four governmental departments (health, sport and recreation, education, social services), five NGOs, four companies from the private sector and one tertiary institution. The task team met on six occasions at the NDOHs offices and held a number of teleconferences between February and May 2005. The main agenda items for these meetings were to $(i)$ explore the nature and feasibility of the campaign; (ii) plan the introduction of Vuka SA to the national parliament; and (iii) plan the launch of the campaign.

One of the first and most important decisions reached by the task team was that 'Move for your Health' would not be restricted to one day's celebrations, but should be ongoing promoting the benefits of PA. Secondly, the campaign was branded 'Vuka SA - Move for your health' and was to form part of the NDOH's healthy lifestyles initiative. Vuka is the Nguni (indigenous SA language) word for 'wake 
up'. Thus, the campaign aimed to 'wake the nation up' to become more physically active and to promote healthy lifestyles.

\section{Political commitment}

Another pre-requisite for implementing successful national plans for physical activity is a high level of political commitment. ${ }^{13,14}$ In the 2005 budget speech to the National Parliament, the Minister of Health highlighted the burden of NCD in SA, and the importance of healthy lifestyles, including regular PA, for the prevention and management of these conditions. ${ }^{15}$ Prior to the budget speech, the Minister participated in a march through the Cape Town Central Business District to parliament, together with members of the community. Several hundred participants carried posters and banners advocating PA.

This action received national television coverage, including the Minister's call to become more physically active. In this way the general public, together with parliamentarians, were first introduced to Vuka SA in April 2005. These factors, together with the global focus on PA for health, provided a window of opportunity for physical activity advocacy in SA.

\section{Consistent message}

Based on the media exposure obtained at the Minister of Health's budget speech and advocacy by members of the task team, individuals who were interested in becoming part of Vuka SA were provided with an information booklet. This booklet detailed the background of 'Move for Health' from the WHO, the rationale for the campaign and a guide to implementation.

Task team members subsequently distributed the booklet among their constituencies, along with an additional 30 individuals and organisations, who requested copies for distribution. Furthermore, the NDOH distributed the booklet to all their provincial offices to promote local events to support the campaign. Each provincial office played a role in disseminating the booklet to their stakeholders, including community health centres and schools. Therefore, a consistent and clear message was disseminated, ensuring that all stakeholders were promoting 30 minutes of PA on at least 5 days per week.

\section{Launch of Vuka SA}

The official launch of the campaign took place in May 2005 in Alexandra township, a high-population density and low socioeconomic community in Gauteng province, near Johannesburg. Similar to the Healthy Lifestyles Campaign, the Vuka SA launch began with a $4 \mathrm{~km}$ walk, led by the Minister of Health and representatives from the Departments of Education and Sport and Recreation. About 1000 adults and children participated in health screening and in various sporting and physical activities at the stadium. The media had a strong presence and the Minister of Health, representatives from the WHO in-country office, tertiary institutions, NGOs, the National Department for Education and members of the public were interviewed during the morning's television broadcast. Vuka SA activities were also implemented by the provincial departments of health and these local events allowed for broader dissemination of the campaign message. ${ }^{16}$

\section{Vuka SA workshop}

The aim of the launch was to disseminate the Vuka SA message. However, Baumann et al. have shown that mass media campaigns are generally more successful if there is a downstream community component. ${ }^{17}$ In this case, a workshop was subsequently held for PA practitioners interested in promoting PA for health. Invitations were sent to NGOs and health promotion officers from the provincial departments of health.

Two workshops were arranged by the task team, and co-funded by the private healthcare sector. The first one was for decision makers and managers, and the second for teachers, coaches and health workers responsible for implementing community-based programmes and promoting regular PA. The main aims of the workshops were to provide delegates with practical advice to promote and implement Vuka SA in their constituencies. Positioning the workshops together with a national sports medicine conference allowed the task team to attract more delegates. The 150 delegates were divided into four discussion groups around:

- factors affecting the implementation of programmes promoting PA

- the need for evaluating the impact and effectiveness of these programmes

- opportunities for working with other themed initiatives within the $\mathrm{NDOH}$

- how to best integrate initiatives from different sectors to prevent duplication and to maximise the reach of the message.

Television and written media representatives were present and conducted interviews with the Minister of Health and workshop attendees, and were aired on the afternoon news bulletin that same day. ${ }^{18}$

International Physical Activity and Public Health Course (IPAPH) Following the workshop, and with a view to increasing national and regional capacity for implementation and evaluation of physical activity programmes for health, the first International Course for Physical Activity and Public Health in Africa was held in March 2007, through the cooperative agreement between the US Centers for Disease Control and Prevention (CDC) and the International Union of Health Promotion and Education, and in conjunction with the University of Cape Town. ${ }^{19}$ The 3.5-day curriculum was designed to aid PA practitioners, advocates, epidemiologists, public health and health promotion specialists, physical educationalists, policy makers and programme directors, concerning all issues related to physical activity and public health, with a specific focus on surveillance, policy development, interventions and evaluation.

Attendees included more than 40 representatives from the private sector, NGOs, tertiary institutions and governmental departments. In addition, representatives from other African countries, Nigeria, Uganda, Zambia, Kenya, Côte d'Ivoire, Tanzania and Botswana were also in attendance. An important outcome of the course was the interest expressed in developing an African network related to PA and public health.

\section{African Physical Activity Network (AFPAN)}

Subsequent to the IPAPH course, the African Physical Activity Network (AFPAN) was formed. AFPAN aimed to establish a network of organisations from various sectors, across Africa, with the common goal of increasing the population prevalence of PA. The primary aim was to share experiences and PA advocacy, and to provide a platform for new regional projects and initiatives. In addition, it was envisaged that the sharing of programmes and lessons learnt would strengthen 
existing initiatives and also lead to the development of best-practice models which were relevant to the African continent.

AFPAN made limited progress between 2007 and 2009, due in large measure to limited resources. However, in April 2010 a programme coordinator was appointed by a tertiary academic institution, which revived the nascent network. Subsequently the AFPAN website was created (www.essm.uct.ac.za/afpan/index.htm), newsletters were sent to members representing 11 African countries (between 2010 and 2011), and a PA policy audit among African countries was initiated. This network is part of the Global Alliance for Physical Activity (GAPA).

\section{Vuka SA: 2007 - 2010}

Subsequent to the launch in 2005 and the workshop in 2007, there have been continued activities and events linked to Vuka SA. However, these have been sporadic and limited data are available on the reach of these activities. Examples of events include the SA Pharmacy Council linking Pharmacy Week in 2007 with Vuka SA. Provincial activities such as the 2008 Gauteng Vuka SA sports day have also been sustained. Other initiatives include the Don Locke fun run, which has adopted Move for Health as its theme, and had approximately four schools participating in 2006 and more than 40 schools in 2010, in the Western Cape Province.

\section{Discussion}

Vuka SA provided an opportunity for various governmental departments and stakeholders to work together with the aim of increasing South Africans' levels of PA. The launch and subsequent workshops functioned as a platform for the sustained implementation of the campaign. However, the implementation has been sporadic since 2007. Monitoring and evaluation of Vuka SA activities have not been systematic and are limited, and as a result there are no current measures of national or regional reach and impact.

\section{Achievements}

The NDOH's Healthy Lifestyles campaign provided a vehicle to promote regular PA at a provincial and national level. Provincial health promotion departments have continued to implement Vuka SA-linked activities since the launch in 2005. For example, the Western Cape and Gauteng provinces trained health workers in the benefits of PA and leading PA sessions at the local health care centres. However, it should be recognised that the extent to which programmes have been implemented varies from province to province, with some having very few activities.

The establishment of partnerships between governmental, NGOs, the private sector and tertiary institutions was at least partially successful. In SA, private companies contributed towards the cost of launching the campaign and the workshops which were attended by stakeholders, representing a broad range of interests.

\section{Challenges}

There was no consultative national plan for the promotion of PA throughout this process, although there was tacit support for such a plan from various stakeholders. The development of national policies and setting programme goals for a predetermined time period have been identified as important components of promoting populationbased PA programmes. ${ }^{14}$ Government is perhaps best placed to facilitate the development and implementation of these national plans. ${ }^{14}$
There is a need for evaluation of this and other PA and health initiatives $\bigotimes$ through evaluation of existing programmes there may be an opportunity to generate practice-based evidence.

\section{Summary}

The Vuka SA campaign was initiated in 2005 and despite some difficulty gaining momentum and reach, progress was made. The media were receptive to providing coverage, thereby providing opportunities for increased awareness for the PA and health message. This message was well received and has enjoyed inter-sectoral collaboration between governmental, NGO, private companies and tertiary institutions.

The future of the campaign involves the development of a consultative national plan for PA, which is currently under way, and generating a stronger and unified message to the SA public to raise awareness and increase the prevalence of PA. Research measuring the effectiveness of the various messages and events associated with promoting health through PA in SA, towards changing knowledge, attitudes and behaviour will be undertaken.

Acknowledgements. The authors would like to acknowledge the support for Vuka SA from the National Departments of Health, Education, Sport \& Recreation, and Social Development. We would also like to thank Mr N Ntuli from the $\mathrm{NDOH}$ for providing some insight during the preparation of this manuscript.

\section{References}

1. Campanini B, ed. WHO Report 2002. Reducing Risks Promoting Healthy Life. Geneva: World Health Organization, 2002.

2. Bradshaw D, Groenewald P, Laubscher R, et al. Initial burden of disease estimates for South Africa, 2000. S Afr Med J 2003;93(9):682-688

3. Guthold R, Ono T, Strong KL, Chatterji S, Morabia A. Worldwide variability in physical inactivity a 51-country survey. Am J Prev Med 2008;34(6):486-494.

4. Reddy SP, Swart D, Jinabhai CC, et al. Umthenthe Uhlaba Usamila - The South African Youth Risk Behaviour Survey 2002. Cape Town: South African Medical Research Council, 2003.

5. Joubert J, Norman R, Lambert EV, et al. Estimating the burden of disease attributable to physical inactivity in South Africa in 2000. S Afr Med J 2007;97 (8 Pt 2):725-731.

6. Government Gazette SA. National Sport and Recreation Act 19551, 1998

7. Boshoff G. Barefoot sports administrators: Laying the foundations for sports development in South Africa. Journal of Sport Management 1997;11:10.

8. Martin SB, Morrow JR, Jr., Jackson AW, Dunn AL. Variables related to meeting the CDC/ACSM physical activity guidelines. Med Sci Sports Exerc 2000;32(12):2087-2092.

9. Matsudo V, Matsudo S, Andrade D, et al. Promotion of physical activity in a developing country: the Agita Sao Paulo experience. Public Health Nutr 2002;5(1A):253-261.

10. World Health Day 2002: Move for Health. http://www.who.int/world-health-day/ previous/2002/en/ (accessed 1 January 2011)

11. Minister of Health. Speech given during the World Health Day Celebration. http:// www.doh.gov.za/docs/sp/2002/sp0407.html (accessed 1 January 2011).

12. Steyn KFJ, Temple N. Chronic diseases of lifestyle in South Africa, 1995 - 2005. In Physical Activity and Chronic Diseases of Lifestlye in South Africa. Cape Town: South African Medical Research Council, 2006.

13. Magnusson R. Non-communicable diseases and global health governance: enhancing global processes to improve health development. Global Health 2007;3(2).

14. Bull FC, Pratt M, Shephard RJ, Lankenau B. Implementing national population-based action on physical activity--challenges for action and opportunities for international collaboration. Promot Educ 2006;13(2):127-132. PMID:17017290.

15. Minister of Health. Budget Speech, 2005. http://www.doh.gov.za/show.php?id=937 (accessed 1 January 2011)

16. Tshabalala-Msimang M. Statement on the Move for Health launch press conference, 2005. http://www.doh.gov.za/show.php?id=923 (accessed 1 January 2011).

17. Bauman AE, Nelson DE, Pratt M, Matsudo V, Schoeppe S. Dissemination of physical activity evidence, programs, policies, and surveillance in the international public health arena. Am J Prev Med 2006;31(4):S57-65.

18. Tshabalala-Msimang M. Speech at the Move for Health National Workshop, 2005. http://www.doh.gov.za/show.php?id=899 (accessed 1 January 2011)

19. International Physical Activity and Public Health Course. http://www.essm.uct.ac.za/ health_pubhealth.html (accessed 1 August 2012) 